\title{
Characterization of downwelling radiance measured from a ground-based microwave radiometer using numerical weather prediction model data
}

\author{
M.-H. Ahn ${ }^{1}$, H. Y. Won ${ }^{1}$, D. Han ${ }^{1}$, Y.-H. Kim ${ }^{2}$, and J.-C. Ha ${ }^{2}$ \\ ${ }^{1}$ Department of Atmospheric Science and Engineering, Ewha Womans University, Ewha-Yeodae-Gil 52, \\ Seodaemoon-Gu, Seoul, Republic of Korea \\ ${ }^{2}$ National Institute of Meteorological Sciences, Korea Meteorological Administration, 33, Seohobuk-ro, \\ Seogwipo Jeju-do, Republic of Korea
}

Correspondence to: M.-H. Ahn (terryahn65@ewha.ac.kr)

Received: 11 February 2015 - Published in Atmos. Meas. Tech. Discuss.: 29 April 2015

Revised: 23 December 2015 - Accepted: 12 January 2016 - Published: 27 January 2016

\begin{abstract}
The ground-based microwave sounding radiometers installed at nine weather stations of Korea Meteorological Administration alongside with the wind profilers have been operating for more than 4 years. Here we apply a process to assess the characteristics of the observation data by comparing the measured brightness temperature $\left(T_{\mathrm{b}}\right)$ with reference data. For the current study, the reference data are prepared by the radiative transfer simulation with the temperature and humidity profiles from the numerical weather prediction model instead of the conventional radiosonde data. Based on the 3 years of data, from 2010 to 2012, we were able to characterize the effects of the absolute calibration on the quality of the measured $T_{\mathrm{b}}$. We also showed that when clouds are present the comparison with the model has a high variability due to presence of cloud liquid water therefore making cloudy data not suitable for assessment of the radiometer's performance. Finally we showed that differences between modeled and measured brightness temperatures are unlikely due to a shift in the selection of the center frequency but more likely due to spectroscopy issues in the wings of the $60 \mathrm{GHz}$ absorption band. With a proper consideration of data affected by these two effects, it is shown that there is an excellent agreement between the measured and simulated $T_{\mathrm{b}}$. The regression coefficients are better than 0.97 along with the bias value of better than $1.0 \mathrm{~K}$ except for the $52.28 \mathrm{GHz}$ channel which shows a rather large bias and variability of -2.6 and $1.8 \mathrm{~K}$, respectively.
\end{abstract}

\section{Introduction}

The potential benefits of ground-based remote sensing instruments such as ceilometer, cloud radar, wind profiler, and passive radiometers are quite well understood and have attracted attention to the continuous efforts for an improvement (Wilczak et al., 1998; WMO, 2006; Cimini et al., 2015). Among these instruments, the ground-based microwave sounding radiometer (hereafter the radiometer) which takes measurement of the downwelling radiances (in the form of brightness temperature, $T_{\mathrm{b}}$ ) in the microwave region has been used to obtain the vertical information of temperature $(T)$ and humidity $(q)$ (Cimini et al., 2006; Löhnert and Maier, 2012; Cadeddu et al., 2013). Its cost efficiency, the capability of autonomous operation, and high temporal resolution with the relatively high accuracy are the most important advantages that have attracted a variety of users. For example, Knupp et al. (2009) show that the high temporal resolution data from the radiometer could resolve the rapidly changing thermodynamic structure of transitioning boundaries, including cold fronts, gust fronts, bores, and gravity waves. It is a significant potential benefit of the radiometer over radiosondes to be able to detect the thermodynamic changes occurring on very short time scales, on the order of 1-10 min, which are far too short to be captured by radiosondes.

On the other hand, the radiometer is also characterized by its limited information contents which are mainly located in the lower atmosphere and by the limited vertical resolu- 
tion (Löhnert et al., 2009; Candlish et al., 2012; Cadeddu et al., 2013). Due to the limitation of information contents contained within the lower atmosphere, the retrieval accuracy of the radiometer usually decreases with increasing altitude (Cadeddu et al., 2002; Hewison, 2007). Also, as the radiometer provides the volumetric measurement while the radiosonde measures the point value with the higher vertical resolution, the radiometer often fails to capture a sharp temperature change, such as the shallow inversion layer (Ware et al., 2003; Löhnert and Maier, 2012). To overcome these limitations, several efforts such as combining with satellite observation (Westwater et al., 1985; Ho et al., 2002), utilizing other ground-based remote sensing instruments (Han and Westater, 1995; Löhnert et al., 2008, 2009), and combination with the numerical weather prediction (NWP) model (Gaussiat et al., 2007) have been applied with a considerable improvements, although not a consolidated approach has been established.

With the expected applications to the nowcasting and utilizations for the NWP model, Korea Meteorological Administration (KMA) has been operating nine ground-based radiometers since as early as April 2009. The observation sites are selected to complement the radar wind profilers which do not provide the vertical thermodynamic information. Although there have been several attempts to utilize the radiometers in research and operational applications (Ha et al., 2010; Jeon et al., 2008; Won et al., 2009), the application has been limited, partly due to the lack of the instrument characterization or little understanding of the derived products. Indeed, since the beginning of the operation a thorough investigation to characterize the measured data or to conduct a rigorous validation of the derived products have not been undertaken. Thus, for a better utilization, characterization of the instrument calibration through the analysis of the measured radiance data is highly desired.

Here, we apply a process to characterize the observation data, $T_{\mathrm{b}}$, for a better understanding of the instrument calibration and to improve our understanding of the characteristics of the radiometer products. To take best advantage of the radiometers, i.e., easily operate them without human intervention, most of the radiometers are operated continuously without interruption except for when the regular absolute calibration should be conducted. On the other hand, as there is no additional reference instrument to be used for the direct comparison, we need to find an indirect approach to characterize the observation data. Thus, we utilized a vicarious calibration approach which compares the measured data with the reference data obtained from the simulation of a radiative transfer model (RTM). For the RTM simulation, we use the $T$ and $q$ profiles from the NWP models instead of radiosonde observation to overcome the limitation due to the small number of collocated radiosonde data and to test feasibility of the NWP models for such a purpose. Indeed, application of the NWP model results for the characterization of the radiometer data has been used before, although it is only done for unique occasions (Liljegren and Lesht, 1996; Cadeddu et al., 2013; Güldner, 2013).

The paper is organized as follows. Data used for the characterization along with the methodology including a short description of the radiative transfer model are introduced in Sect. 2. The comparison results between the measured and simulated $T_{\mathrm{b}} \mathrm{S}$ are shown in Sect. 3, and the assessments of possible causes of the large bias between the simulated and measured $T_{\mathrm{b}}$ values are described in Sect. 4. The paper is summarized in Sect. 5 with a few lists of the planned future works.

\section{Methodology and data}

\subsection{Methodology}

One of the straight-forward approaches for the characterization of the raw data from an instrument would be the direct comparison with data from the well-characterized reference instrument. As that is not available for the radiometers installed in the KMA weather stations, we use an alternative approach, by comparing the measured radiances with the simulated ones (Löhnert and Maier, 2012; Güldner, 2013). As the results of the comparison depend on the accuracy of the simulated radiances, we need a reliable RTM and the accurate $T$ and $q$ profiles which are used for the input data of RTM. Although well-characterized RTM is readily available (see below), it is not usually the case for the high quality $T$ and $q$ profiles, especially for a sufficiently long time period required for the correct characterization. As the main purpose of the radiometer installation (with the collocated wind profiler) was to fill the gaps in the network of upper weather observation, radiosonde observation is not available for the radiometer sites. Thus, here we attempt to use the $T$ and $q$ profiles from the NWP models (hereafter called NWP data) for the calculation of the simulated $T_{\mathrm{b}}$. To make sure that the NWP data are accurate enough to be used as the reference data, we first compare the NWP data to the $T$ and $q$ profiles obtained by the limited number of radiosonde observations. The simulated $T_{\mathrm{b}}$ from the RTM simulation with the inputs from the NWP data and from the radiosonde data are also inter-compared to check the effects on the simulated $T_{\mathrm{b}}$ caused by the difference of the $T$ and $q$ profiles. We, then, assess the calibration characteristics by comparing the measured $T_{\mathrm{b}}$ (hereafter $T_{\mathrm{b}}^{\mathrm{M}}$ ) with the simulated $T_{\mathrm{b}}$.

\subsection{Data}

\subsubsection{Microwave radiometer}

The $T_{\mathrm{b}}^{\mathrm{M}}$ is obtained by a ground-based microwave sounding radiometer manufactured by RPG Radiometer Physics $\mathrm{GmbH}$ (hereafter the RPG radiometer) which has been operating at the Changwon weather station $\left(35.17^{\circ} \mathrm{N}\right.$ and $128.57^{\circ} \mathrm{E}$, at $37.15 \mathrm{~m}$ above the sea level) of South Korea 
Table 1. Error statistics of the simulated $T_{\mathrm{b}}\left(T_{\mathrm{b}}^{\mathrm{E}}\right.$ and $\left.T_{\mathrm{b}}^{\mathrm{K}}\right)$ obtained from the radiative transfer simulation with the input profiles of temperature and humidity from the NWP data, compared to the simulated $T_{\mathrm{b}}\left(T_{\mathrm{b}}^{R}\right)$ with the input profiles obtained by the radiosonde. (Here and afterwards, the bias and variability are obtained from the average and standard deviation of difference between the two values, respectively). $N$ indicates the number of collocated NWP data with radiosonde profile data (Unit: K).

\begin{tabular}{lrrr|rrr}
\hline \multirow{2}{*}{$\begin{array}{l}\text { Frequency } \\
(\mathrm{GHz})\end{array}$} & \multicolumn{3}{c|}{ ECMWF $(N=67)$} & \multicolumn{3}{c}{ KLAPS $(N=117)$} \\
\cline { 2 - 7 } & bias & variability & $R$ & bias & variability & $R$ \\
\hline 51.26 & 0.66 & 1.51 & 0.99 & -0.25 & 1.57 & 0.99 \\
52.28 & 0.64 & 1.19 & 0.99 & -0.27 & 1.37 & 0.99 \\
53.86 & 0.40 & 0.52 & 1.00 & -0.28 & 1.05 & 0.99 \\
54.94 & 0.25 & 0.50 & 1.00 & -0.25 & 0.86 & 0.99 \\
56.66 & 0.33 & 0.75 & 1.00 & -0.08 & 0.98 & 0.99 \\
57.30 & 0.37 & 0.81 & 1.00 & -0.02 & 1.02 & 0.99 \\
58.00 & 0.41 & 0.85 & 1.00 & 0.03 & 1.04 & 0.99 \\
\hline
\end{tabular}

since 2010. The RPG radiometer has a total of 14 observation frequencies, 7 around the $22.24 \mathrm{GHz}$ water vapor resonance line, and another 7 for the $60 \mathrm{GHz}$ oxygen absorption band (RPG, 2013; also refer Table 1). The seven channels around $22.24 \mathrm{GHz}$ are used for the water vapor profiling, while the seven oxygen channels are used for the temperature profiling. Additional products such as the total precipitable water and the cloud liquid water are also derived by the combination of all 14 channels (Solheim et al., 1998; Li et al., 1997; Won et al., 2009). The $T_{\mathrm{b}}$ data are obtained every $2-3 \mathrm{~s}$ with infrequent interruption for the gain calibration, looking at the internal blackbody installed inside of the RPG radiometer (RPG, 2013).

The $T_{\mathrm{b}}^{\mathrm{M}}$ is obtained by conversion of the measured detector voltage using the calibration equation with the coefficients prepared during the absolute calibration process. For the absolute calibration, four reference signals from the warm and cold targets with the addition of the noise diode signal to each target are used to derive the four calibration coefficients, including gain coefficient, non-linearity factor, background noise, and temperature of the noise diode (RPG, 2013). The warm target is internally installed blackbody and the liquid nitrogen (LN2) is used for the cold target. It is recommended to conduct the absolute calibration whenever the radiometer is newly installed, relocated, or for every 6 months. During the absolute calibration, the most serious source of uncertainty is known to come from frost formed on the surface of reflector which sends the radiation coming from the cold target to the radiometer. Thus, it is recommended to conduct the absolute calibration with special care during the humid environment. On the other hand, the real time calibration is done by frequent observation of internal blackbody and the noise diode which adds an additional signal to the input radiance to provide a reference radiance value for the absolute calibration (RPG, 2013). During the study period, from 1 January 2010 to 31 December 2012, $T_{\mathrm{b}}$ data are continuously available except for a few occasions in- cluding a short interruption during the early observation and during the short and regular absolute calibration periods.

\subsubsection{Vertical profiles of temperature and humidity}

As a part of assessment test for the void upper air observation over the south-eastern part of Korea Peninsula to the weather forecasting, automatic radiosonde equipment has been operated at the Changwon Weather Station since 2012. The radiosonde is Vaisala RS-92 GPS with known accuracy of better than $0.5 \mathrm{~K}$ (Nash et al., 2011; Miloshevich et al., 2009). As the radiosondes have been launched for the experimental purpose, the temporal resolution is variable (from 3 to $12 \mathrm{~h}$ ), and the observation period is also variable. For example, during the year 2012, there were two intensive observation periods, one from 25 to 29 June and another from 24 to 29 August. During these periods, radiosondes were launched eight times a day, but this number was reduced to twice a day during the other observation period. Radiosonde data are available dating back to June 2012, and the number of radiosonde data used for the current study is 117 . These limited number of available radiosonde data are compared with two different sets of the NWP data, one from hourly KLAPS (Korea Local-area Analysis and Prediction System; NIMR, 2012; Lee et al., 2010) analysis data and another from the 6-hourly ECMWF (European Centre for Medium-range Weather Forecasts) analysis data (Richardson et al., 2013) with the spatial resolution of $0.25^{\circ}$. The NWP data are linearly interpolated to the RPG radiometer site using the surrounding four grid points. For the vertical grid points, the NWP profiles are vertically interpolated to match the radiometer retrieval altitudes at below $10 \mathrm{~km}$, while the original grid points are used for the above $10 \mathrm{~km}$.

A direct comparison in terms of the bias and variability (bias and variability are obtained from the average and standard deviation of the difference between the two values, respectively) between the available radiosonde and the NWP data are summarized in Fig. 1. The biases of the tempera- 
(a)

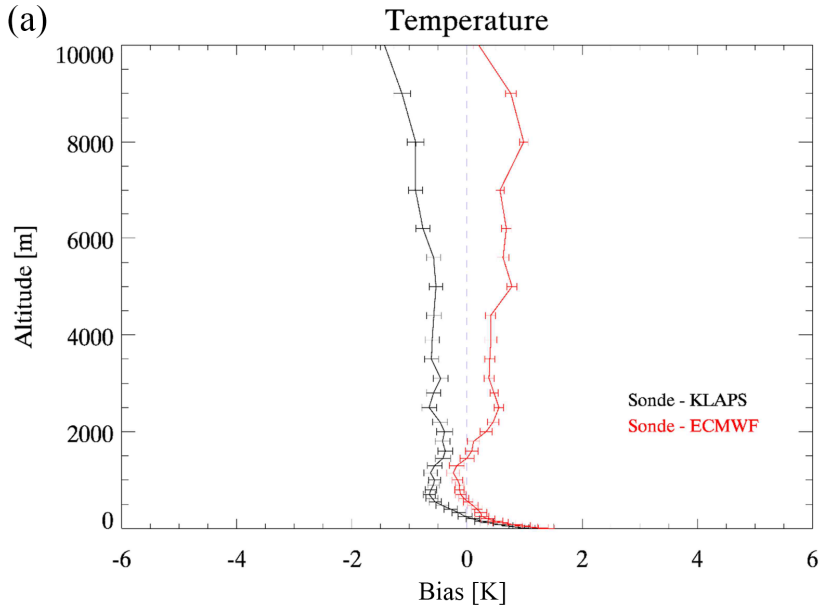

(b)

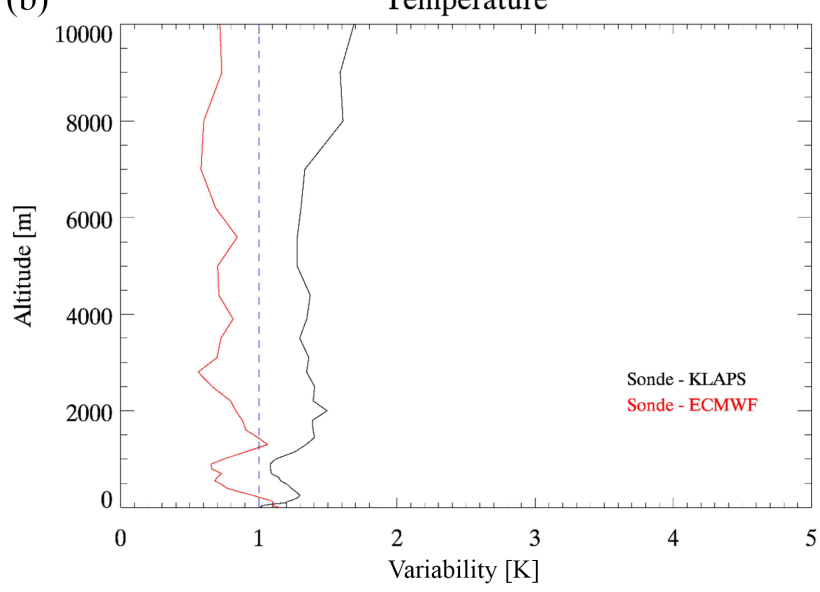

Figure 1. The bias (a) and the variability (b) of the temperature profiles of the NWP data compared to the radiosonde data obtained from June 2012 to July 2013 (total of 117 and 67 data points for KLAPS and ECMWF, respectively). The horizontal error bar in the bias profile represents the standard deviation of mean (red and black solid lines are for the comparison between radiosonde vs. the ECMWF profile and radiosonde vs. the KLAPS data, respectively).

ture profile between the radiosonde and the NWP data are all within $1 \mathrm{~K}$ for at least below about $9 \mathrm{~km}$ except near the ground where as large as $1.5 \mathrm{~K}$ is found for both NWP data. Overall, the ECMWF data show a warm bias, while the KLAPS data have the cold bias, with the almost the same absolute magnitude. However, if we check the variability as shown in Fig. 1b, the ECMWF data show the smaller values. Furthermore, the ECMWF data show a quite stable variability with the altitude, while an increase with the increasing altitude is shown in the KLAPS data. Thus, from the direct comparison of the temperature profile, it is assessed that the two NWP data show a satisfactory bias characteristic in relation with the radiosonde uncertainty, while the variability characteristics of the ECMWF data is better than that of the KLAPS data.

To assess the effects of these bias and variability characteristics to the simulated $T_{\mathrm{b}}$, the RTM simulation with vertical profiles from both radiosonde and NWP data are conducted and the results are compared (see Sect. 3.1).

\subsection{Radiative transfer model}

For the calculation of $T_{\mathrm{b}}$, we use the MonoRTM, a RTM that has been developed for the ARM (Atmospheric Radiation Measurement) program (Clough et al., 2005; Payne et al., 2011). The model can be run to simulate upwelling or downwelling radiance at the given number of monochromatic frequencies for a range of user specified conditions including viewing geometries. Although it can incorporate the default cloud models or user-provided cloud parameters for the cloudy condition, simulations for the current study are done with the clear sky assumptions. Thus, it should be noted that the simulated $T_{\mathrm{b}}$ values are all considered as the clear sky $T_{\mathrm{b}}$ values. Utilizing the same physics as LBLRTM, the current version (V5.0) takes advantage of numerous improvements in the computational efficiency, the HITRAN2012 spectroscopy - except for the $60 \mathrm{GHz}$ oxygen lines from Tretyakov et al. (2005), and increased flexibility (refer the home page at: http://rtweb.aer.com/monortm_frame.html for details). The accuracy for the water vapor channels, obtained from the comparison with the two frequency radiometer at an ARM sites, are known to be better than $0.28 \mathrm{~K}$ including both RTM and measurement error (Clough et al., 2005). On the other hand, the accuracy obtained from the comparison with the well-calibrated radiometers at the oxygen bands are estimated to have better than $1 \mathrm{~K}$ root mean square difference (Cadeddu et al., 2007). However, the comparison is made at the cold and dry Arctic conditions and further investigations for different climatic conditions are suggested (Cadeddu et al., 2007).

\section{Comparison Results}

To characterize the measured $T_{\mathrm{b}}$, we first assess the comparability of the simulated $T_{\mathrm{b}}$ by using the $T$ and $q$ profiles obtained both from radiosonde and the NWP data at seven frequencies of the oxygen absorption band. After the assessment, the $T_{\mathrm{b}}^{\mathrm{M}}$ values are compared with the simulated $T_{\mathrm{b}}$ values. To better understand the cloud effects on $T_{\mathrm{b}}^{\mathrm{M}}$, comparisons are made for both all sky and clear sky conditions.

\subsection{Comparison of the simulated $T_{\mathrm{b}} \mathrm{S}$}

Similar to the comparisons made for the $T$ and $q$ profiles between the radiosonde and the NWP data, the simulated $T_{\mathrm{b}}$ obtained with those input profiles are compared and summarized in Table 1 and Fig. 2. As expected from the temperature comparisons, $T_{\mathrm{b}} \mathrm{s}$ simulated with the ECMWF data (hereafter 

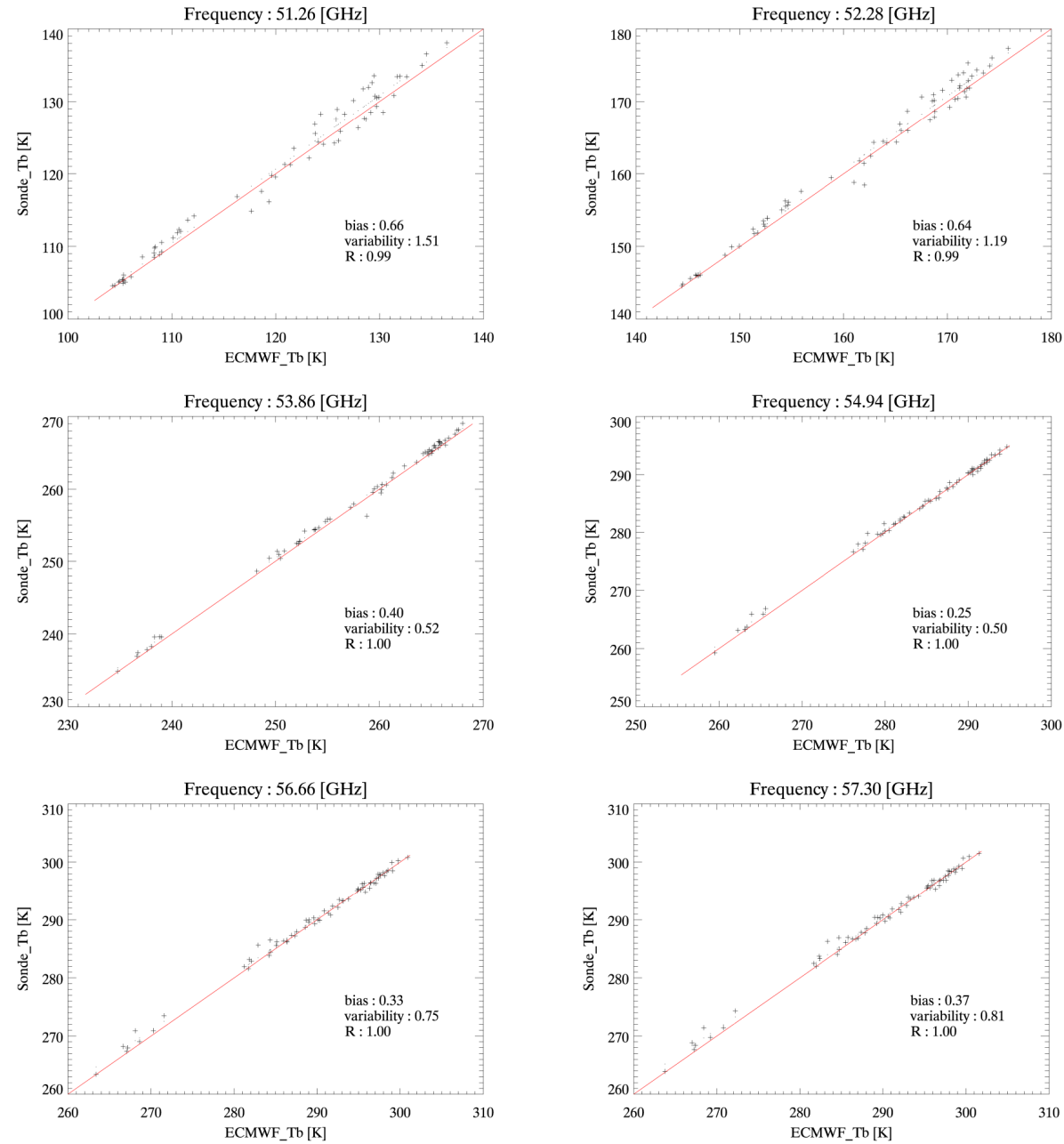

Figure 2. Scatter diagram between the simulated $T_{\mathrm{b}}$ using ECMWF data $\left(T_{\mathrm{b}}^{\mathrm{E}}\right)$ and radiosonde data $\left(T_{\mathrm{b}}^{R}\right)$ for the lower 6 frequencies $(N=67)$.

$T_{\mathrm{b}}^{\mathrm{E}}$ ) show the positive bias while those with the KLAPS data (hereafter $T_{\mathrm{b}}^{\mathrm{K}}$ ) show the negative bias (Table 1). The absolute bias value is relatively larger at the lower frequencies, about $0.7 \mathrm{~K}$, compared to the higher frequencies, about $0.4 \mathrm{~K}$ for EMCWF and $0.03 \mathrm{~K}$ for KLAPS data. Similarly, the variability decreases with increasing frequency for both NWP data, having better than $1 \mathrm{~K}$ at most of the frequencies except at the two lower frequencies having as large as $1.6 \mathrm{~K}$ at the $51.26 \mathrm{GHz}$ channel for the both NWP data.

As expected from the temperature comparison, the variability for $T_{\mathrm{b}}^{\mathrm{K}}$ is larger than that of $T_{\mathrm{b}}^{\mathrm{E}}$. In case of the correlation coefficients, the simulated $T_{\mathrm{b}} \mathrm{s}$ of both NWP models show quite a good linear relationship with the radiosonde simulation, having better than 0.99 at most frequencies. Along with the bias and variability characteristics, the linearity characteristics between the $T_{\mathrm{b}}$ s provide a sufficient background for the further utilization of the simulated $T_{\mathrm{b}}$ with the NWP data. Thus, the characterization of the radiometer data could be extended to the cases when radiosonde observations are not available. For example, the radiometer data obtained before June 2012 and the other eight radiometers installed at the KMA weather stations are not accompanied with the radiosonde observations. Furthermore, based on the bias, variability, and correlation characteristics, the $T_{\mathrm{b}}^{\mathrm{E}}$ is mainly used for the further discussions.

\section{2 $\quad$ Measured $T_{\mathrm{b}}$ vs. simulated $T_{\mathrm{b}}$}

Here, we present the comparison results made between $T_{\mathrm{b}}^{\mathrm{M}}$ and $T_{\mathrm{b}}^{\mathrm{E}}$. Table 2 summarizes the error characteristics in terms of the bias, variability, and correlation coefficients for all frequencies of oxygen absorption band. The comparison is obtained with the different data sets prepared after applying different selection criteria. For example, when no selection criteria are applied, the data set includes all of the data obtained during the study period (except the rain-flagged data determined by the rain sensor installed on the top of the RPG radiometer). Thus, the error statistics represent the characteristics the original $T_{\mathrm{b}}^{\mathrm{M}}$ data. Seemingly, the biases look acceptable, showing the largest bias of $3.8 \mathrm{~K}$ at $51.26 \mathrm{GHz}$ 
Table 2. Summary of the comparison results between $T_{\mathrm{b}}^{\mathrm{E}}$ and $T_{\mathrm{b}}^{\mathrm{M}}$ obtained from the data set without any screening process (original), after removing cloudy data (clear sky), and after further screening of data produced during the faulty calibration (calibration). The number of data points for the three cases are 4085, 2392, and 1767, respectively (Unit: K).

\begin{tabular}{lrrr|rrr|rrr}
\hline $\begin{array}{l}\text { Frequency } \\
(\mathrm{GHz})\end{array}$ & \multicolumn{3}{c|}{$\begin{array}{c}\text { Original } \\
(N=4085)\end{array}$} & \multicolumn{3}{c|}{$\begin{array}{c}\text { Clear sky } \\
(N=2392)\end{array}$} & \multicolumn{3}{|c}{$\begin{array}{c}\text { Calibration } \\
(N=1767)\end{array}$} \\
\cline { 2 - 11 } & bias & variability & $R$ & bias & variability & $R$ & bias & variability & $R$ \\
\hline 51.26 & 3.8 & 24.6 & 0.65 & -4.2 & 6.6 & 0.86 & -0.6 & 2.3 & 0.97 \\
52.28 & 0.8 & 19.1 & 0.68 & -5.5 & 5.2 & 0.91 & -2.6 & 1.8 & 0.99 \\
53.86 & 1.5 & 4.8 & 0.92 & 0.0 & 1.7 & 0.99 & 1.0 & 0.6 & 1.00 \\
54.94 & 0.4 & 1.2 & 0.99 & 0.2 & 0.8 & 1.00 & 0.6 & 0.5 & 1.00 \\
56.66 & -0.3 & 1.0 & 0.99 & -0.4 & 0.9 & 1.00 & -0.1 & 0.9 & 1.00 \\
57.30 & -0.4 & 1.0 & 0.99 & -0.4 & 0.9 & 1.00 & -0.2 & 0.8 & 1.00 \\
58.00 & -0.4 & 1.0 & 0.99 & -0.4 & 0.9 & 1.00 & -0.2 & 0.9 & 1.00 \\
\hline
\end{tabular}
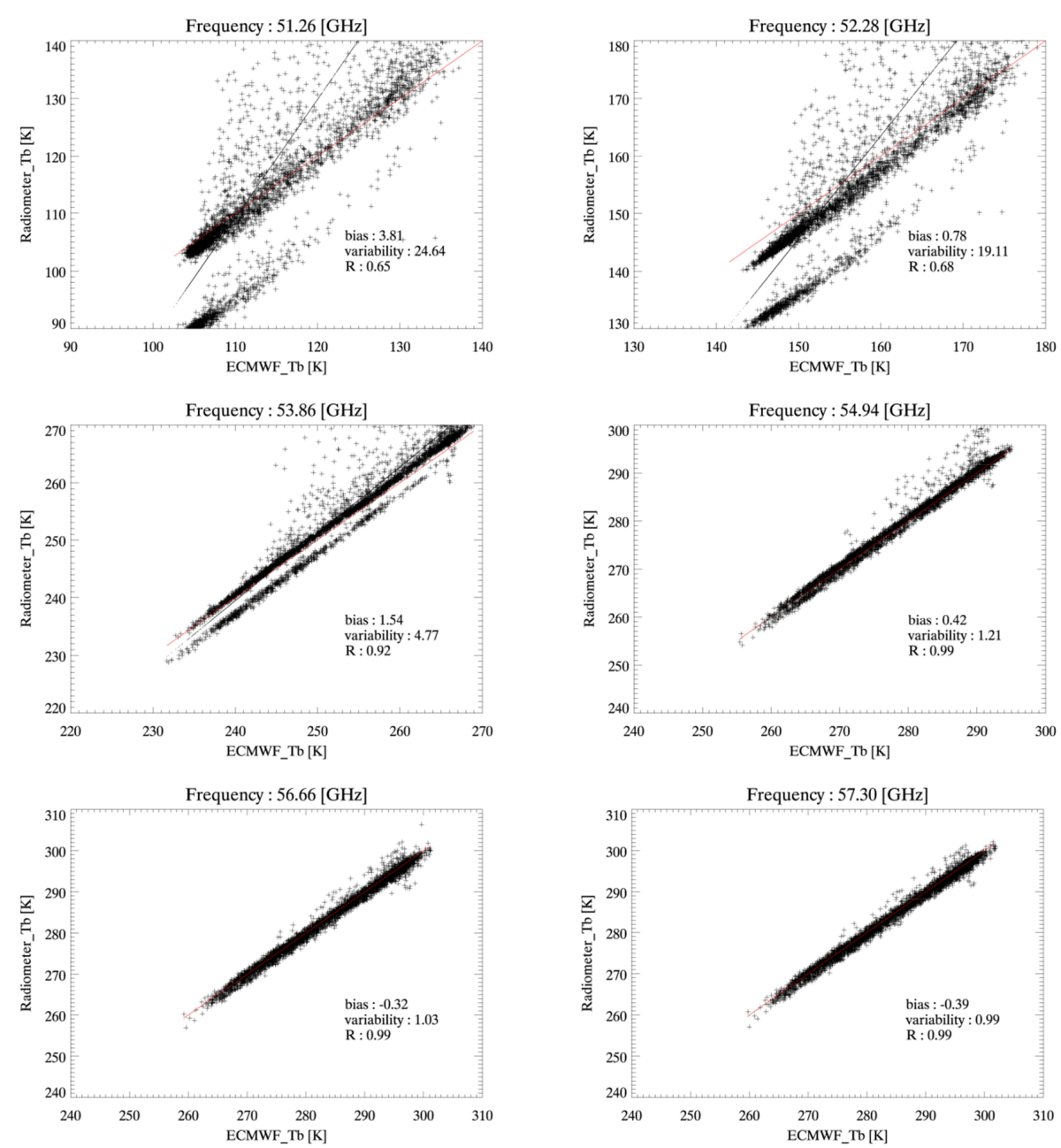

Figure 3. Comparison between the $T_{\mathrm{b}}^{\mathrm{M}}$ and $T_{\mathrm{b}}^{\mathrm{E}}$ (red line is the one-to-one line and $N=4063$ ).

channel with much smaller values at the higher frequencies. However, the variability and the correlation coefficient, especially at the lower three channels, show quite a large variability (mainly due to the cloud contamination) and a rather weak correlation (mainly due to the faulty absolute calibration); this confirms that cloudy conditions cannot be used to characterize the $T_{\mathrm{b}}^{\mathrm{M}}$ data, unless the absorption of liquid wa- 
Table 3. The comparison results of the different simulated $T_{\mathrm{b}} \mathrm{s}$ and observed $T_{\mathrm{b}}$ for clear and well-calibrated conditions for only when the radiosonde data is available (total of 26 cases).

\begin{tabular}{lrrr|rrr|rrr}
\hline Frequency & \multicolumn{3}{c|}{ Sonde } & \multicolumn{3}{c|}{ ECMWF } & \multicolumn{3}{c}{ KLAPS } \\
\cline { 2 - 9 }$(\mathrm{GHz})$ & bias & variability & $R$ & bias & variability & $R$ & bias & variability & $R$ \\
\hline 51.26 & -0.42 & 2.03 & 0.98 & 0.01 & 2.83 & 0.97 & -1.29 & 2.52 & 0.98 \\
52.28 & -2.52 & 1.51 & 0.99 & -2.00 & 2.10 & 0.99 & -3.12 & 1.81 & 0.99 \\
53.86 & 0.51 & 0.56 & 1.00 & 0.97 & 0.51 & 1.00 & 0.43 & 0.64 & 1.00 \\
54.94 & 0.19 & 0.66 & 1.00 & 0.49 & 0.54 & 1.00 & 0.07 & 0.51 & 1.00 \\
56.66 & -0.52 & 0.75 & 1.00 & -0.14 & 0.73 & 1.00 & -0.66 & 0.84 & 1.00 \\
57.30 & -0.68 & 0.75 & 1.00 & -0.24 & 0.75 & 1.00 & -0.78 & 0.87 & 1.00 \\
58.00 & -0.73 & 0.82 & 1.00 & -0.24 & 0.86 & 1.00 & -0.80 & 0.92 & 1.00 \\
\hline
\end{tabular}

ter is considered and a good estimate of the liquid water path is available.

To make sure that the comparison results are not due to the selection of the atmospheric profiles, the comparison made with other simulated $T_{\mathrm{b}} \mathrm{s}$ with the measured $T_{\mathrm{b}}$ are shown in Table 3. Here, the error statistics are estimated using the clear and well-calibrated data obtained for when the radiosonde data are acquired. Although the total number of data matched for these conditions is only 26 , the estimated error statistics show a comparable bias and variability characteristics between $T_{\mathrm{b}} \mathrm{s}$ with the radiosondes and ECMWF data, while $T_{\mathrm{b}} \mathrm{s}$ with the KLAPS data shows a slightly larger variability, which could also be traced back to the intercomparison between the simulated $T_{\mathrm{b}} \mathrm{s}$.

For a better understanding of the effects due to the data screening, the scatter plots between $T_{\mathrm{b}}^{\mathrm{M}}$ and $T_{\mathrm{b}}^{\mathrm{E}}$ for the first six frequency channels are analyzed as shown in Fig. 3 (the $58 \mathrm{GHz}$ channel shows an almost identical characteristic with that of the $57.3 \mathrm{GHz}$ channel and the results are not shown). From the scatter diagram, several interesting characteristics including the cloud effects are identified. First of all, channels at lower frequencies such as 51.26, 52.28, and $53.86 \mathrm{GHz}$ show two distinct data groups, with one group having relatively more data points compared to the other group. The distinction is much clearer at the lowest frequency and diminishes with the increasing frequency, becoming indistinguishable at channels higher than $56.66 \mathrm{GHz}$. The reason for the separation turns out to be due to an apparent error in the absolute calibration done by using the LN2 during the early period of the instrument operation (see below).

Another interesting feature at these lower channels is that both the two separated groups are away from the one-to-one line (the red line) that represents a perfect match between the $T_{\mathrm{b}}^{\mathrm{M}}$ and $T_{\mathrm{b}}^{\mathrm{E}}$. For example, at the $51.26 \mathrm{GHz}$ channel, one denser group is closer to the one-to-one line, while another group is much further down from the one-to-one line. On the other hand, at the $52.28 \mathrm{GHz}$ channel, both groups are located below the one-to-one line. It should be mentioned here that the separation and offset from the one-to-one line also occurs at the higher frequencies such as the $54.94 \mathrm{GHz}$ channel, although it is not as clearly visible as the other three lower channels. Although previous studies (Hewison et al., 2006; Löhnert and Maier, 2012) indicate this kind of offset feature is possible due to the uncertainty in the frequency assignment, detailed analysis with the simulated data given in Sect. 4 indicates the other way for the radiometer used for the current study.

The $T_{\mathrm{b}}^{\mathrm{M}}$ characteristics are more clearly revealed in the time series of the difference between $T_{\mathrm{b}}^{\mathrm{M}}$ and $T_{\mathrm{b}}^{\mathrm{E}}$, i.e., $T_{\mathrm{b}}^{\mathrm{M}}-$ $T_{\mathrm{b}}^{\mathrm{E}}$, hereafter called the $T_{\mathrm{b}}$ difference, as shown in Fig. 4 . First of all, there are many data points having large positive values which are more prominent at the lower frequencies. The deviation is as high as $160 \mathrm{~K}$ at the $51.26 \mathrm{GHz}$ channel. Once again, this large positive difference is easily explained by the cloud effects which add more radiation to the background clear sky radiance, resulting in the much higher $T_{\mathrm{b}}^{\mathrm{M}}$ compared to $T_{\mathrm{b}}^{\mathrm{E}}$ which represents the clear sky condition (Turner, 2007; Cadeddu and Turner, 2011). The cloud effects decrease with the increasing frequency due to the radiation by the oxygen absorption/emission resulting in the increased contribution from the warm lower atmospheric emission to the $T_{\mathrm{b}}^{\mathrm{M}}$. Even with the limited effects, the cloud contaminated data is revealed as the scattered data points in Fig. 3. Thus, for an accurate assessment of the calibration characterization, we need to select data points free from cloud contamination, even at these oxygen channels. For the cloudy data screening, an algorithm using the downwelling infrared radiation measured by the IRT radiometer along with the surface temperature and humidity is used (Ahn et al., 2015a).

Another prominent feature from the time series shown in Fig. 4 is that the $T_{\mathrm{b}}$ difference during a certain period, such as the period from 10 September 2010 to 31 March 2011, is much larger than the other periods. Furthermore, the difference is clearly offset and discontinuous from the difference shown for the other time periods, implying an event that introduces the systematic bias and continues for a rather long time period has happened. Based on the instrument maintenance records, the absolute calibrations were indeed performed in 10 September 2010 and in 31 March 2011 which 

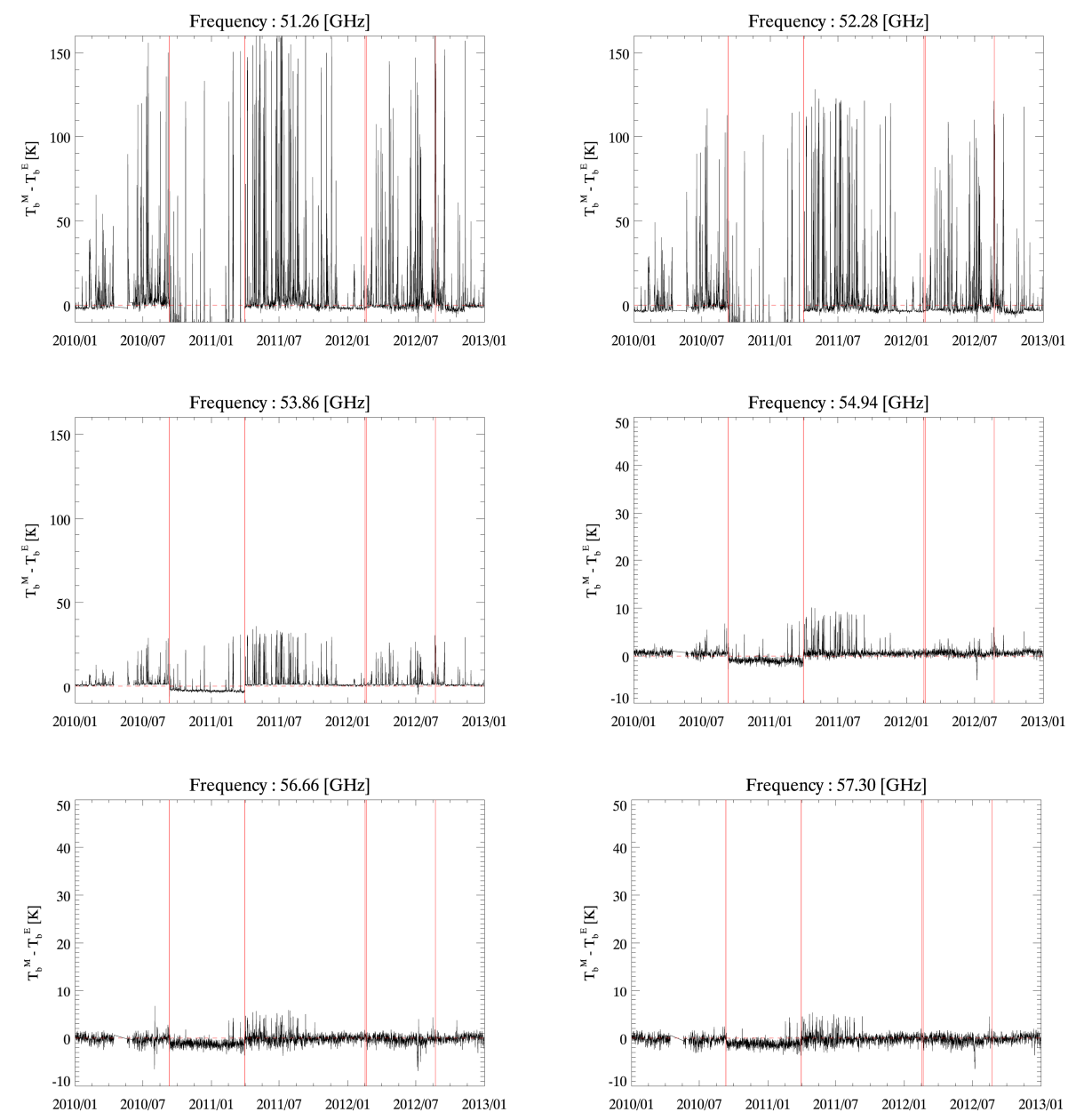

Figure 4. Time series of the difference between the $T_{\mathrm{b}}^{\mathrm{M}}$ and $T_{\mathrm{b}}^{\mathrm{E}}$ for the six oxygen bands (note the different range of $y$ axis). The red vertical bars denote the date when the absolute calibration is performed.

are exactly coincident with the points having the large discrepancy. Thus, it is highly suspected that the discontinuity in the error characteristics is mainly due to the uncertainty caused by the mistakes that occurred during the absolute calibration done on 10 September 2010. To make sure that these kinds of error characteristics are not caused by the uncertainties in the simulated $T_{\mathrm{b}}^{\mathrm{E}}$, the time series of difference between $T_{\mathrm{b}}^{\mathrm{M}}$ and $T_{\mathrm{b}}^{\mathrm{K}}$ (from the KLAPS model) are also checked and it is confirmed that the same characteristics are also present (not shown). Although there is a potential way to rectify erroneous data caused by the faulty absolute calibration, we just treat the data as it is for the further characterizations.

Overall, the error statistics improve with the progress of the data screening, especially at the lower three frequencies. As shown in Fig. 5, which shows the scatter plot between $T_{\mathrm{b}}^{\mathrm{E}}$ and $T_{\mathrm{b}}^{\mathrm{M}}$ for the four lower frequency channels with the data set without the cloudy and the faulty calibration period, the variability shows a significant improvement at the 51.26 (52.28) $\mathrm{GHz}$ channel, from 6.6 (5.2) to $2.3 \mathrm{~K}(1.8 \mathrm{~K})$, along with a slight improvement of the correlation coefficient, from
$0.86(0.91)$ to $0.97(0.99)$. At the higher frequencies, the variability improvements are not that dramatic, although it shows an improvement, at all five higher channels, the variability is better than $1 \mathrm{~K}$. In case of bias, although overall improvements at all channels are evident giving almost $0 \mathrm{~K}$ value, two channels, 53.86 and $54.94 \mathrm{GHz}$ channels, show a slight degradation. Furthermore, the bias values at the 52.28 and $53.86 \mathrm{GHz}$ channels still show a significant $T_{\mathrm{b}}$ difference and different characteristics (positive bias at the $53.86 \mathrm{GHz}$ channel) compared to the previous study (Maschwitz et al., 2013), which are further described in next section.

\section{Possible causes of the systematic bias}

As shown in Fig. 5, even after removal of data contaminated by the faulty calibration and cloud contamination, $T_{\mathrm{b}}^{\mathrm{M}}$ and $T_{\mathrm{b}}^{\mathrm{E}}$ show a clear offset from the one-to-one line with the relatively small variability, particularly at 52.28 and $53.86 \mathrm{GHz}$ channels. The apparent systematic bias is also shown in the 

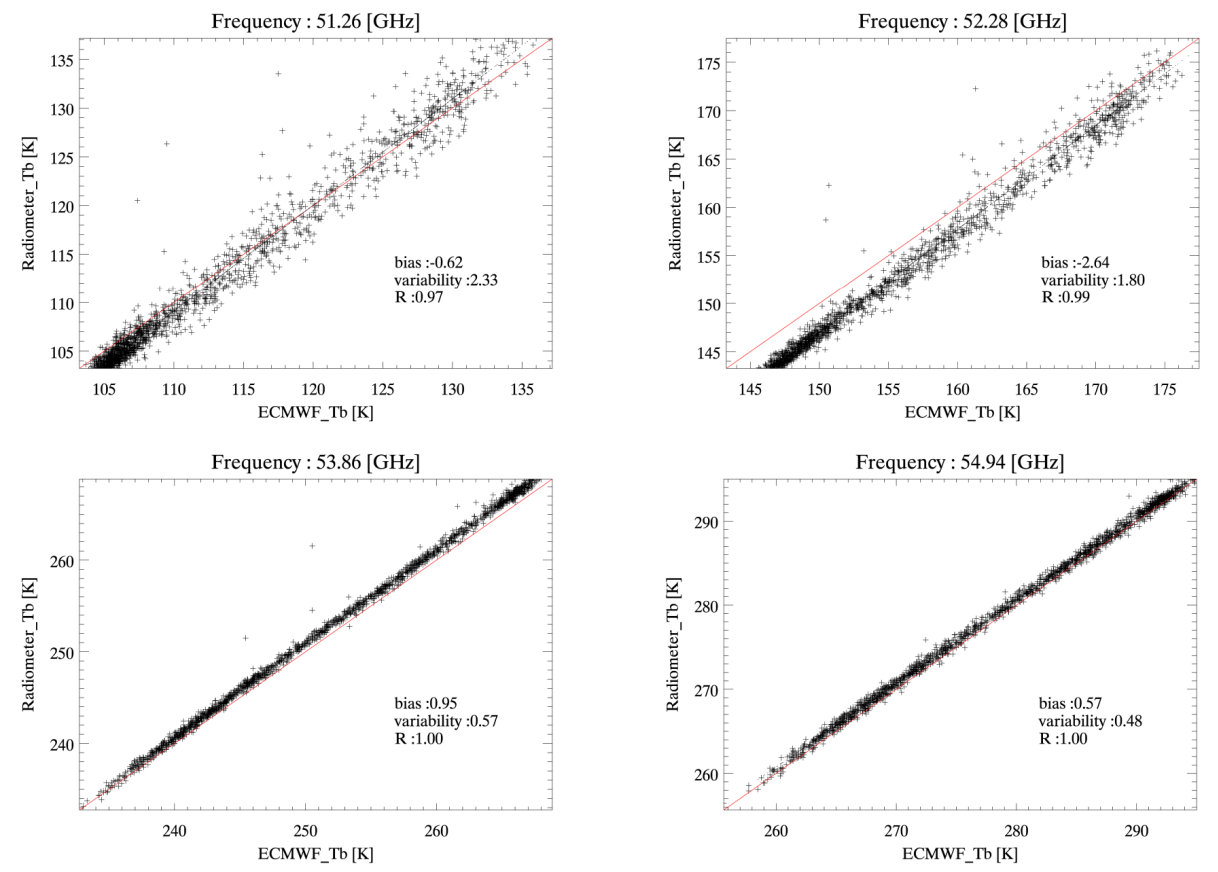

Figure 5. Scatter diagram of $T_{\mathrm{b}}^{\mathrm{E}}$ and $T_{\mathrm{b}}^{\mathrm{M}}$ obtained after removing data with the erroneous calibration and contaminated by clouds.

comparison made with other simulated data including radiosonde and KLAPS analysis in addition to the other similar microwave radiometers (Hewison et al., 2006; Löhnert and Maier, 2012); their plausible causes are traced to center-frequency offset among other sources of uncertainties such as the band pass effect, band width effect, and so on. However, as mentioned also in Löhnert and Maier (2012) and Maschwitz et al. (2013), the RPG radiometer (Generation 2) used for current study is known to have uncertainty of $1 \mathrm{MHz}$. Thus, for an assessment of the proposition of the frequency shift as the source of the systematic bias, a simple approach which searches a new frequency value that gives the least difference between $T_{\mathrm{b}}^{\mathrm{M}}$ and $T_{\mathrm{b}}^{\mathrm{E}}$ is applied followed by the error analysis.

To find the new frequency, we first select the clear sky $T_{\mathrm{b}}^{\mathrm{M}}$ with free of the faulty absolute calibration to minimize uncertainties other than the frequency uncertainty. Then the NWP data corresponding to the observation time of the clear sky $T_{\mathrm{b}}^{\mathrm{M}}$ are used to simulate the high-resolution $(10 \mathrm{MHz}$ interval) simulated $T_{\mathrm{b}}$ values as a function of frequency values. Here, it should be mentioned that the simulation resolution is coarser than the known uncertainty of $1 \mathrm{MHz}$. However, as the interested frequencies, 52.28 and $53.86 \mathrm{GHz}$, are in the valleys of absorption line centers (e.g., 52.021, 52.542, $53.066,53.595,54.130 \mathrm{GHz}$ ) where absorption is smooth with frequency due to the pressure broadening at the ground, the $10 \mathrm{MHz}$-interval simulation would give meaningful results. Once the simulated $T_{\mathrm{b}}$ spectrum is prepared, the $T_{\mathrm{b}}^{\mathrm{M}}$ is used to find the best matching frequency value which gives the least difference between the $T_{\mathrm{b}}^{\mathrm{M}}$ and simulated $T_{\mathrm{b}}$. As the
Table 4. The adjusted frequency for the two lower frequencies derived from both the ECMWF and KLAPS profiles. The adjusted frequency is obtained by taking averages of the frequencies that give the best match between the measured $T_{\mathrm{b}}\left(T_{\mathrm{b}}^{\mathrm{M}}\right)$ and simulated $T_{\mathrm{b}}$ $\left(T_{\mathrm{b}}^{\mathrm{E}}\right.$ or $\left.T_{\mathrm{b}}^{\mathrm{K}}\right)$. The numbers within the parentheses is averaged difference and its standard deviation.

\begin{tabular}{lcc}
\hline \multirow{2}{*}{ Original } & \multicolumn{2}{c}{ Adjusted Frequency $(\mathrm{GHz})$} \\
\cline { 2 - 3 } Frequency $(\mathrm{GHz})$ & ECMWF & KLAPS \\
\hline 52.28 & $52.24(-0.04 \pm 0.03)$ & $52.23(-0.05 \pm 0.03)$ \\
53.86 & $53.88(0.02 \pm 0.01)$ & $53.87(0.01 \pm 0.01)$ \\
\hline
\end{tabular}

simulated $T_{\mathrm{b}}$ spectrum covers all four frequency channels, the best matching frequency for each channel is simultaneously found. Then, the difference between the known frequency value and newly found frequency value could be considered as the uncertainty in the center frequency. To increase the characterization accuracy, we use all of the selected data and also utilize both the ECMWF and KLAPS data to check the NWP model dependence of the frequency deviation. The results from all selected individual cases are used to derive the bias and variability and are summarized in Table 4 .

From the Table 4, several interesting conclusions could be derived. First of all, the results from the two NWP models provide almost the same frequency shift and its variability, verifying the model inputs would not produce the systematic bias, at least for the current study. Secondly, to remove the $T_{\mathrm{b}}$ difference between the $T_{\mathrm{b}}^{\mathrm{M}}$ and simulated $T_{\mathrm{b}}$, a frequency shift of as much as $-0.04(0.02) \mathrm{GHz}$ for the 52.28 

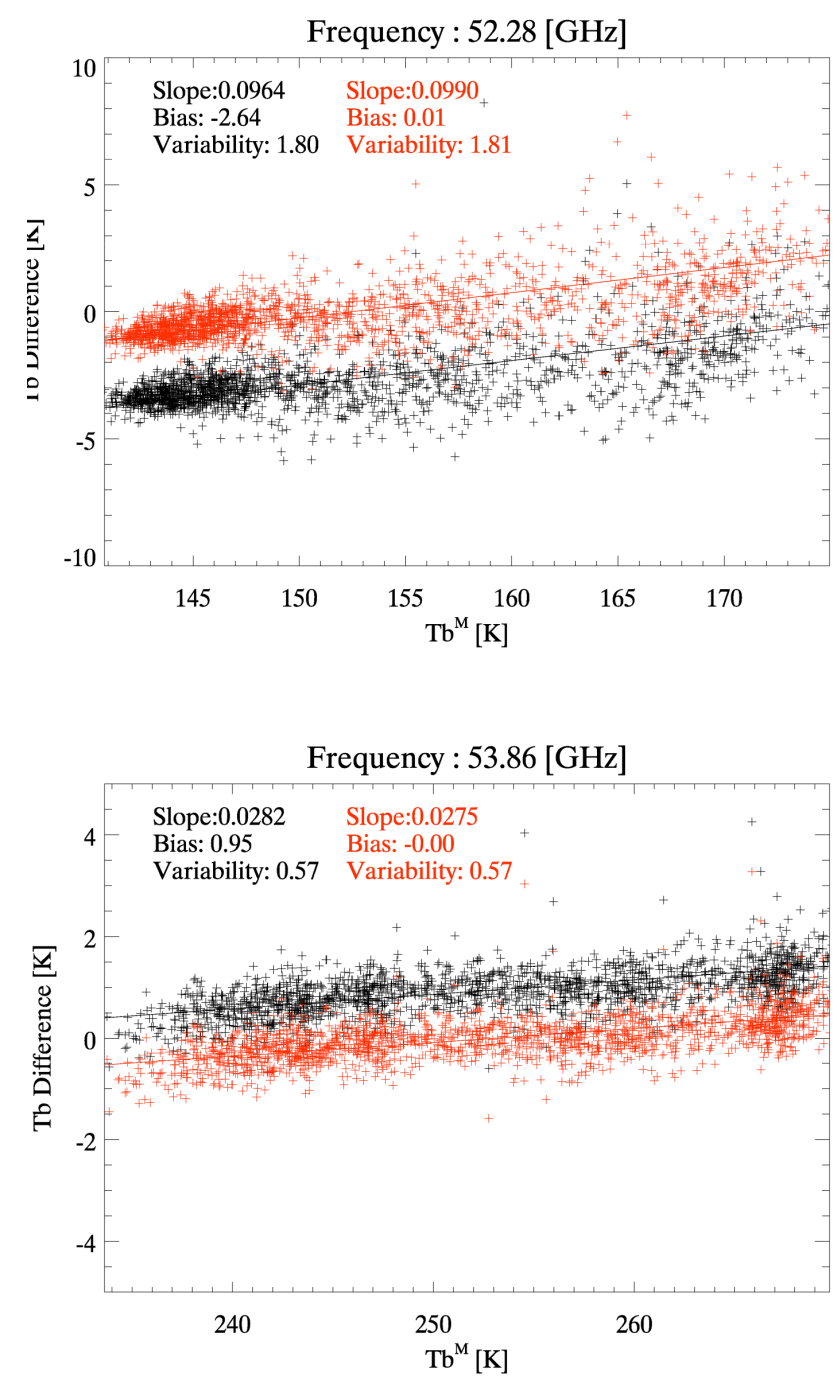

Figure 6. The $T_{\mathrm{b}}$ difference as a function of $T_{\mathrm{b}}^{\mathrm{M}}$ (black crosses: $T_{\mathrm{b}}^{\mathrm{M}}-T_{\mathrm{b}}^{\mathrm{E}}$, red crosses: $T_{\mathrm{b}}^{\mathrm{M}}-T^{\text {new }}$ ) for the data set obtained after removing data with faulty calibration and data contaminated by clouds. The solid lines are the best linear fit.

(53.86) GHz channel is necessary. However, the uncertainties in the estimated frequency shift (given as the variability in the Table 4) show rather large values (as much as $0.03 \mathrm{GHz}$ in the $52.28 \mathrm{GHz}$ ), compared to the known frequency uncertainties of about $1 \mathrm{MHz}$ (Löhnert and Maier, 2012). Thus, to further check whether the $T_{\mathrm{b}}$ difference is indeed due to the frequency uncertainty, the characteristics of the newly derived $T_{\mathrm{b}}^{\mathrm{E}}$ (or $T_{\mathrm{b}}^{\text {new }}$ ), corresponding to the simulated $T_{\mathrm{b}}$ at the shifted frequency (for example, $52.24 \mathrm{GHz}$ instead of the original $52.28 \mathrm{GHz}$ ), are compared to the $T_{\mathrm{b}}^{\mathrm{M}}$. Figure 6 shows the $T_{\mathrm{b}}$ differences, both the original $T_{\mathrm{b}}$ difference (black crosses) and the new $T_{\mathrm{b}}$ difference (i.e., $T_{\mathrm{b}}^{\mathrm{M}}-T_{\mathrm{b}}^{\text {new}}$; red crosses), as a function of the $T_{\mathrm{b}}^{\mathrm{M}}$. With the shifted frequency, average of the $T_{\mathrm{b}}$ difference reduces to almost 0.0 at both channels. However, the variability and the slope (between the $T_{\mathrm{b}}$ dif- ferences vs. $T_{\mathrm{b}}^{\mathrm{M}}$ ) do not show any meaningful change that carries an important meaning. The non-zero slope shown in the original data seemed closely related with the frequency uncertainty (Wu and Yu, 2013; Ahn et al., 2015b), and thus it could be readily argued that the $T_{\mathrm{b}}$ difference is due to the frequency shift. In particular, when the spectral $T_{\mathrm{b}}$ is highly dependent on the frequency such as the case for the two lower channels, a small uncertainty in the center frequency produces a significant uncertainty in the estimated $T_{\mathrm{b}}$ (called frequency sensitivity). Furthermore, the frequency sensitivity increases with increasing target temperature, i.e. $T_{\mathrm{b}}^{\mathrm{M}}$, thus the frequency shift introduces the non-zero slope as shown in the original data (the black crosses). With the same argument, the frequency sensitivity of the new $T_{\mathrm{b}}$ difference should be reduced to 0 values (see the Fig. 5 of Ahn et al., 2015b) because the $T_{\mathrm{b}}^{\text {new }}$ is supposed to be free from the frequency uncertainty. However, as shown in Fig. 6, the red crosses have almost the same slope as the original data (the black crosses) implying the frequency shift does not remedy the large frequency sensitivity shown in the original $T_{\mathrm{b}}$ difference. It should also be noted that the variability of $T_{\mathrm{b}}^{\mathrm{M}}-T_{\mathrm{b}}^{\text {new }}$ does not show any improvement either from the original data (from 1.80 to $1.81 \mathrm{~K}$ for the $52.28 \mathrm{GHz}$ channel). Thus, based on these two characteristics of the $T_{\mathrm{b}}$ difference, it should be concluded that the systematic bias shown in the two channels are not caused by the frequency uncertainty.

On the other hand, such a characteristic of the $T_{\mathrm{b}}$ difference is also known to be introduced by the uncertainties in the spectroscopic data and/or the uncertainty in the absolute calibration of the radiometer (Cimini et al., 2004; Hewison et al., 2006; Cadeddu et al., 2007; Maschwitz et al., 2013). Although it is not possible to provide definitive evidence toward one cause, several aspects of the $T_{\mathrm{b}}$ difference imply the root cause as the uncertainty in the spectroscopic data. First of all, the positive slopes shown in Fig. 6 are all consistent regardless of the input data used for the estimation of the $T_{\mathrm{b}}^{\text {new }}$, i.e. positive slopes are shown when the simulated $T_{\mathrm{b}}$ is obtained with the KLAPS data. Exactly the same characteristics of the spectral sensitivity are also shown in the similar frequency channels used for the Radiometric TP/WVP-3000 instrument (see Fig. 1 of Hewison et al., 2006). Furthermore, the time series of the new $T_{\mathrm{b}}$ difference shown in Fig. 7 shows a clear seasonality and consequently the $T_{\mathrm{b}}^{\mathrm{M}}$ dependence (less variable with negative bias during the wintertime and increased variability with a positive bias during the summer time). The data affected by the faulty absolute calibration further also shows that a calibration error introduces a much different shape of the spectral sensitivity (higher value during the winter time in the $52.28 \mathrm{GHz}$ channel, with no seasonal feature in the $53.86 \mathrm{GHz}$ channel; not shown). However, as described by Maschwitz et al. (2013) the calibration accuracy also decreases with decreasing $T_{\mathrm{b}}^{\mathrm{M}}$ value, and thus for a detailed quantitative analysis, it is required to understand the definitive cause of the discrepancy. 

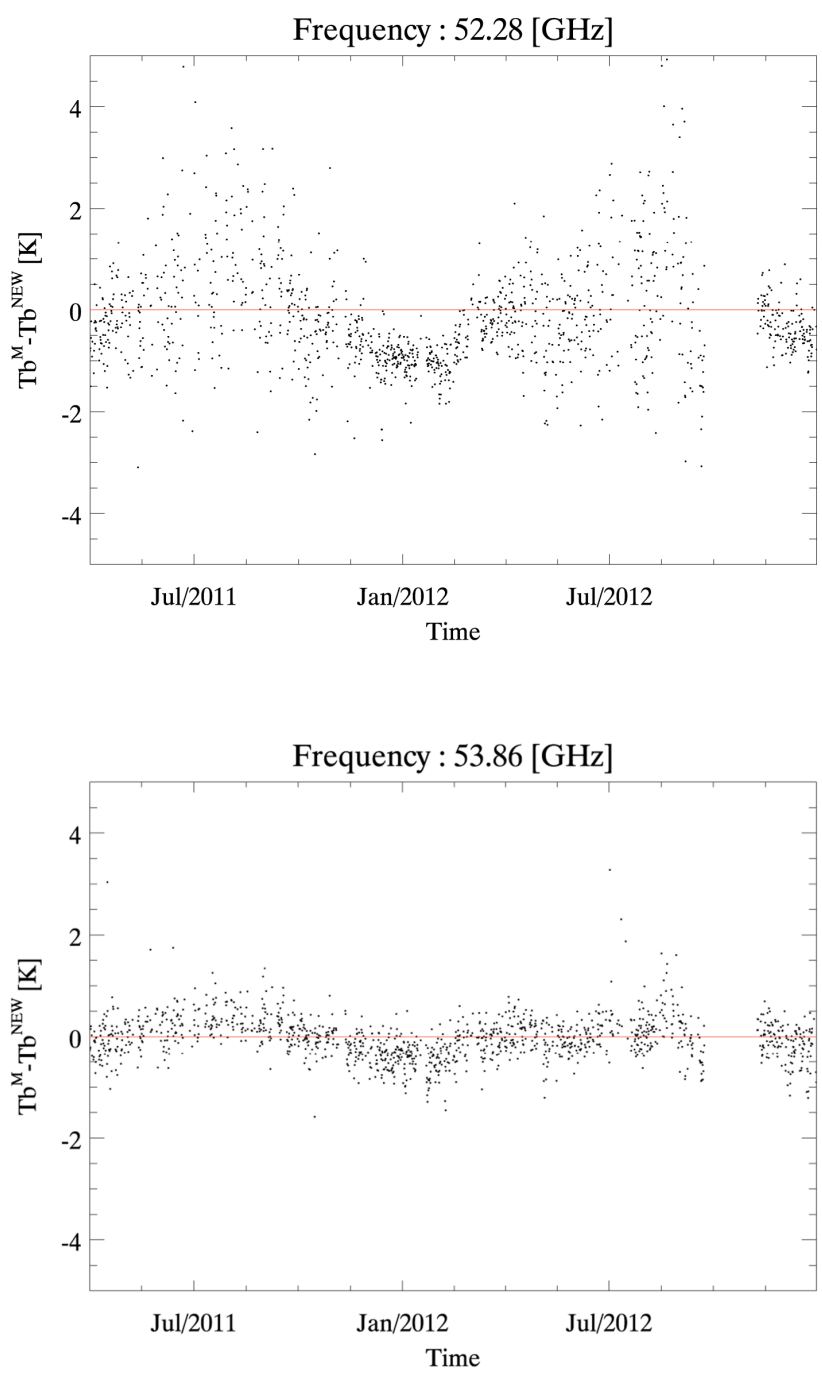

Figure 7. Time series of $T_{\mathrm{b}}^{\mathrm{M}}-T_{\mathrm{b}}^{\text {new }}$ (after the frequency shift). Here, the data affected by the faulty calibration period is excluded for the comparison.

\section{Summary}

Nine ground-based microwave sounding radiometers of KMA have been operating since 2010 without a rigorous sensor characterization. For a better utilization of the measurement data, a quality assessment process on the accuracy of the radiometers has been applied. The reference measurements for this, the simulated downwelling radiances (or $T_{\mathrm{b}} \mathrm{s}$ ), are prepared by the radiative transfer modeling with the $T$ and $q$ profiles from the NWP data instead of the conventional radiosonde observations. Before its application, the simulated $T_{\mathrm{b}}$ with the NWP data is validated with the simulated $T_{\mathrm{b}}$ with the limited number of radiosonde data. With the application of NWP data (from KLAPS and ECMWF), the study period could be extended, and 3 years of measurement data starting from the beginning of the radiometer ob- servation at the Changwon Weather Station since 2010 are utilized.

Direct comparison between the simulated $T_{\mathrm{b}}$ and measured $T_{\mathrm{b}}$ revealed the three important characteristics associated with the instrument calibration. First of all, when the absolute calibration is not properly performed, the inter-comparison between the measured and simulated $T_{\mathrm{b}} \mathrm{S}$ reveals a clear offset in the measured $T_{\mathrm{b}}$, giving large values of bias and variability with the quite low number of correlation coefficient. Secondly, the clouds with an appreciable optical thickness introduce a significant uncertainty in the comparison results which require a solid cloud detection algorithm for a better characterization of the instrument calibration. Finally, with the removal of the data affected by the two important degrading components, the comparison results between the measured and simulated $T_{\mathrm{b}} \mathrm{s}$ agree within the previously known accuracy, better than $1 \mathrm{~K}$ in the bias and variability, except at the two frequency channels, the 52.28 and $53.86 \mathrm{GHz}$ channels which show the bias value of -2.6 and $1.0 \mathrm{~K}$, respectively.

The proposition that uncertainty in the center frequency as the root cause of the bias is rejected by two characteristics shown in the $T_{\mathrm{b}}$ difference. First of all, the dependence of $T_{\mathrm{b}}$ difference on the measured $T_{\mathrm{b}}$ does not disappear even after a new center frequency is applied to derive the $T_{\mathrm{b}}$ difference. Secondly, the uncertainty of the necessary frequency shift to best match the measured $T_{\mathrm{b}}$ and simulated $T_{\mathrm{b}}$ is way too large compared to the known frequency uncertainty. Thus, instead of the frequency uncertainty, the plausible cause for the discrepancy is traced to the spectroscopy data used in the preparation of the simulated $T_{\mathrm{b}}$, in view of the consistent spectral sensitivity shown with the simulated $T_{\mathrm{b}} \mathrm{s}$ with different input profiles and results given by a different type of the radiometer along with the time series of the $T_{\mathrm{b}}$ difference. However, to determine the definitive cause of the discrepancy a detailed quantitative analysis is required.

Even with the limitation, it is clearly shown that the simulated $T_{\mathrm{b}}$ values using the readily available NWP data could well be used for the characterization of the radiometer. With the same application process, we plan to expand the assessment activities to the other radiometers being operated at other weather stations. Through the activities, overall quality of the measurement data along with the identification of necessary improvements for a better utilization of the instruments could be derived. Also, with the microwave sounding radiometer that is manufactured by a different company and has been operating at the same weather station for a limited period of time, we would be in better position to understand the issues related with the $T_{\mathrm{b}}$ difference, such as effects on the temperature retrieval. A similar approach, but with an additional care for the cloudy data, could be used for the water vapor channels. Finally, it should be mentioned here that even the characteristics of instrument calibration could be assessed with the NWP data, it would be always better to have a sufficient number of in situ observation data such as the ra- 
diosonde observation. This would be more important for the evaluation of the retrieval performance.

Acknowledgements. The current work is supported by the "Development and application of technology for weather forecast (NIMR-2012-B-1)" of the National Institute of Meteorological Research (NIMR). The paper is improved significantly thanks to the suggestions and critical reviews given by the anonymous reviewers and the associated editor.

Edited by: D. Cimini

\section{References}

Ahn, M.-H., Han, D., Won, H. Y., and Morris, V.: A cloud detection algorithm using the downwelling infrared radiance measured by an infrared pyrometer of the ground-based microwave radiometer, Atmos. Meas. Tech., 8, 553-566, doi:10.5194/amt8-553-2015, 2015a.

Ahn, M.-H., Lee, S. J., and Kim, D.: Estimation of uncertainties in the spectral response function of the water vapor channel of a meteorological imager, Third International Conference on Remote Sensing and Geoinformation of the Environment (RSCy2015), Proc. SPIE 9535, doi:10.1117/12.2192518, 2015 b.

Candlish, L. M., Raddatz, R. L., Asplin, M. G., and Barber, D. G.: Atmospheric temperature and absolute humidity profiles over the Beaufort Sea and Amundsen Gulf from a microwave radiometer, J. Atmos. Ocean. Tech., 29, 1182-1201, 2012.

Cadeddu, M. P. and Turner, D. D.: Evaluation of water permittivity models from ground-based observations of cold clouds at frequencies between 23 and $170 \mathrm{GHz}$, IEEE T. Geosci. Remote, 49, 2999-3008, 2011.

Cadeddu, M. P., Peckham, G. E., and Gaffard, C.: The vertical resolution of ground-based microwave radiometers analyzed through a multiresolution wavelet technique, IEEE Trans. Geo. Remote Sens., 40, 531-540, 2002.

Cadeddu, M. P., Payne, V. H., Clough, S. A., Cady-Pereira, K., and Liljegren, J. C.: Effect of the oxygen line-parameter modeling on temperature and humidity retrievals from ground-based microwave radiometers, IEEE T. Geosci. Remote, 45, 2216-2222, 2007.

Cadeddu, M. P., Liljegren, J. C., and Turner, D. D.: The Atmospheric radiation measurement (ARM) program network of microwave radiometers: instrumentation, data, and retrievals, Atmos. Meas. Tech., 6, 2359-2372, doi:10.5194/amt-6-2359-2013, 2013.

Cimini, D., Westwater, E. R., Han, Y., Keihm, S. J., Ware, R., Marzano, F. S., and Ciotti, P.: Atmospheric microwave radiative models study based on ground-based multichannel radiometer observations in the 20-60-Ghz band, edited by: Carrothers, D., Proceedings of the 14th ARM Science Team Meeting, Albuquerque, New Mexico, 22-26 March 2004, 1-9, 2004.

Cimini, D., Hewison, T. J., Martin, L., Güldner, J., Gaffard, C., and Marzano, F. S.: Temperature and humidity profile retrievals from ground-based microwave radiometers during TUC, Meteorol. Z., 15, 45-56, 2006.
Cimini, D., Nelson, M., Güldner, J., and Ware, R.: Forecast indices from a ground-based microwave radiometer for operational meteorology, Atmos. Meas. Tech., 8, 315-333, doi:10.5194/amt-8315-2015, 2015.

Clough, S. A., Shephard, M. W., Mlawer, E. J., Delamere, J. S., Iacono, M. J., Cady-Pereira, K., Boukabar, S., and Brown, P. D.: Atmospheric radiative transfer modeling: a summary of the AER codes, J. Quant. Spectrosc. Ra., 91, 233-244, doi:10.1016/j.jqsrt.2004.05.058, 2005.

Gaussiat, N., Hogan, R. J., and Illingworth, A. J.: Accurate liquid water path retrieval from low-cost microwave radiometers using additional information from a lidar ceilometer and operational forecast models, J. Atmos. Ocean. Tech., 24, 1562-1575, 2007.

Güldner, J.: A model-based approach to adjust microwave observations for operational applications: results of a campaign at $\mathrm{Mu}-$ nich Airport in winter 2011/2012, Atmos. Meas. Tech., 6, 28792891, doi:10.5194/amt-6-2879-2013, 2013.

Ha, J.-C., Lee, J.-S., Lee, Y. H., Lee, H.-C., and Chang, D.-E.: Production of the high-resolution reanalysis data using KLAPS, Proceedings of the Spring Meeting of KMS, 29-30 April 2010, Geryong, Korea, 227-228, 2010 (in Korean with English abstract).

Han, Y. and Westwater, E.: Remote sensing of tropospheric water vapor and cloud liquid water by integrated ground-based sensors, J. Atmos. Ocean. Tech., 12, 1050-1059, 1995.

Hewison, T.,: 1D-VAR retrieval of temperature and humidity profiles from a ground-based microwave radiometer, IEEE T. Geosci. Remote, 45, 2163-2168, 2007.

Hewison, T., Cimini, D., Martin, L., Gaffard, C., and Nash, J.: Validating clear air absorption models using ground-based microwave radiometers and vice-versa, Meteorol. Z., 15, 27-36, 2006.

Ho, S.-P., Smith, W., and Huang, H.-L.: Retrieval of atmospherictemperature and water-vapor profiles by use of combined satellite and ground-based infrared spectral-radiance measurements, Appl. Optics, 41, 4057-4069, 2002.

Jeon, E.-H., Kim, Y.-H., Kim, K.-H., and Lee, H.-S.,: Operation and application guidance for the ground-based dual-band radiometer, Atmosphere, 18, 441-458, 2008 (in Korean with English abstract).

Knupp, K. R., Coleman, T., Phillips, D., Ware, R., Cimini, D., Vandenberghe, F., Vivekanandan, J., and Westwater, E.: Groundbased passive microwave profiling during dynamic weather conditions, J. Atmos. Ocean. Tech., 26, 1057-1073, 2009.

Lee, Y. H., Ha, J.-C., Lee, J.-S., Lee, H. C., and Chang, D.-E.: The Korean Local Reanalysis: Preliminary Result (2008-2009), The 3rd THORPEX-Asia Science Workshop and ARC-7 meeting, 35 June 2010, Jeju, Korea, 2010.

Li, L., Vivekanandan, J., Chan, C., and Tsang, L.: Microwave radiometric technique to retrieve vapor, liquid and ice, Part I - Development of a neural network-based inversion method, IEEE T. Geosci. Remote, 35, 224-236, 1997.

Liljegren, J. C. and Lesht, B. M.: Measurements of integrated water vapor and cloud liquid water from microwave radiometers at the DOE ARM Cloud and Radiation Testbed in the US southern Great Plains, Proc. Int. Geophys. Rem. Sens. Symp., 96, 16751677, 1996.

Löhnert, U. and Maier, O.: Operational profiling of temperature using ground-based microwave radiometry at Payerne: 
prospects and challenges, Atmos. Meas. Tech., 5, 1121-1134, doi:10.5194/amt-5-1121-2012, 2012.

Löhnert, U., Crewell, S., Krasnov, O., O’Connor, E., and Russchenberg, H.: Advances in continuously profiling the thermodynamic state of the boundary layer: integration of measurements and methods, J. Atmos. Ocean. Tech., 25, 1251-1266, 2008.

Löhnert, U., Turner, D. D., and Crewell, S.: Ground-based temperature and humidity profiling using spectral infrared and microwave observations. Part I: Simulated retrieval performance in clear-sky conditions, J. Appl. Meteorol. Climatol., 48, 10171032, 2009.

Maschwitz, G., Löhnert, U., Crewell, S., Rose, T., and Turner, D. D.: Investigation of ground-based microwave radiometer calibration techniques at $530 \mathrm{hPa}$, Atmos. Meas. Tech., 6, 2641-2658, doi:10.5194/amt-6-2641-2013, 2013.

Miloshevich, L. M., Vömel, H., Whiteman, D. N., and Leblanc, T.: Accuracy assessment and correction of Vaisala RS92 radiosondes water vapor measurements, J. Geophys. Res., 114, D11305, doi:10.1029/2008JD011565, 2009.

Nash, J., Oakley, T., Vömel, H., and Wei, L.: WMO intercomparison of high quality radiosonde systems, Yangjiang, China, 12 July-3 August 2010, WMO/TD-No. 1580, WMO, 248 pp., 2011.

NIMR: Development and application of technology for weather forecast(IV), National Institute of Meteorological Research, Seoul, Republic of Korea, Report-11-1360395-000350-09, 2012 (in Korean).

Payne, V. H., Mlawer, E. J., Cady-Pereira, K. E., and Moncet, J.-L.: water vapor continuum absorption in the microwave, IEEE T. Geosci. Remote, 49, 2194-2208, doi:10.1109/TGRS.2010.2091416, 2011.

Richardson, D. S., Bidlot, J., Ferranti, L., Haiden, T., Hewson, T., Janousek, M., Prates, F., and Vitart, F.: Evaluation of ECMWF forecasts, including 2012-2013 upgrades, technical memorandum No. 710, ECMWF, Reading, Berkshire, UK, 55 pp., 2013.

RPG: Instrument Operation and Software Guide - Principle of Operation and Software Description for RPG standard single-polarization radiometers, RPG, 128 pp., available at http://www.radiometer-physics.de/rpg/html/docs/RPG_ MWR_STD_Software_Manual.pdf, last access: 27 April 2015.
Solheim, F., Godwin, J. R., Westwater, E. R., Han, Y., Keihm, S. J., Marsh, K., and Ware, R.: Radiometric profiling of temperature, water vapor and cloud liquid water using various inversion methods, Radio Sci., 33, 393-404, 1998.

Tretyakov, M. Y., Koshelev, M. A., Dorovshikh, V. V., Makarov, D. S., and Rosenkranz , P. W.: 60-GHz oxygen band: Precise broadening and central frequencies of fine-structure lines, absolute absorption profile at atmospheric pressure, and revision of mixing-coefficients, J. Mol. Spectrosc., 231, 1-14, 2005.

Turner, D. D.: Improved ground-based liquid water path retrievals using a combined infrared and microwave approach, J. Geophys Res., 112, D15204, doi:10.1029/2007JD008530, 2007.

Ware, R., Carpenter, R., Güldner, J., Liljegren, J., Nehrkorn, T., Solheim, F., and Vandenberghe, F.: A multichannel radiometric profiler of temperature, humidity, and cloud liquid, Radio Sci., 38, 8079, doi:10.1029/2002RS002856, 2003.

Westwater, E., Zhenhui, W., Grody, N., and McMillin, L.: Remote sensing of temperature profiles from a combination of observations from the satellite-based Microwave Sounding Unit and the ground-based profiler, J. Atmos. Ocean. Tech., 2, 97-109, 1985.

Wilczak, J. M., Gossard, E. E., Neff, W. D., and Eberhard, W. L.: Ground-based remote sensing of the atmospheric boundary layer: 25 years of progress, in: Boundary-Layer Meteorology 25th Anniversary Volume, 1970-1995, edited by: Garratt, J. R. and Taylor, P. A., Kluwer Academic Publishers, 321-349, 1998.

WMO: Operational aspects of different ground-based remote sensing observing techniques for vertical profiling of temperature, wind, humidity and cloud structure: a review, WMO/TD-No. 1309, 37 pp., 2006.

Won, H. Y., Kim, Y.-H., and Lee, H.-S.: An application of brightness temperature received from a ground-based microwave radiometer to estimation of precipitation occurrences and rainfall intensity, Asia Pac. J. Atmos. Sci., 45, 55-69, 2009.

$\mathrm{Wu}, \mathrm{X}$. and Yu, F.: Correction for GOES imager spectral response function using GSICS - Part I: Theory, IEEE Trans. Geosci. Remote Sens., 51, 1215-1223, 2013. 